\title{
REVISITING ACCOUNTING IN THE KNOWLEDGE-BASED ECONOMY
}

Manivannan Senthil Velmurugan

\begin{abstract}
The purpose of this paper attempts to give an explanation of why accounting bodies are hesitant to embrace new intellectual capital valuation and reporting models that have sprung up in the last decade, in spite of the fact that accounting standards are generally ill-suited to cater for intangibles. Despite some resistance, this paper highlights the commendable efforts of those pushing for change, and even offers recommendations to standard setters and accountants at large as to the way forward in approaching the complex dynamics involving the measurement of intellectual capital. The information of the research project was gathered from various secondary sources of data. The sources range from: industry trade journals; practitioner accounting journals; and academic publications, to give both practical and theoretical views on the subject matter. A comparison will first be made that looks into the limitations of existing financial models and the subsequent implications of ignoring IC in financial statements versus the significance of accounting for IC. The second part entails comparing IC valuation techniques using conventional reporting standards against proposed new reporting methodologies. From this discussion, a conclusion will be drawn which will include a proposition of a way forward in addressing IC.
\end{abstract}

Keywords: Knowledge Management, Intellectual Capital, Knowledge-based economy, Accounting, Accountant, Finance, Accounting Principles.

\section{Introduction}

Today knowledge is a major driver of corporate wealth and a primary competitive factor in business. Worldwide, the economy is changing thanks to an unprecedented revolution in technology. This age is marked by nations making the transition towards a knowledge-based economy (KBE), due to the increasing global interdependency and rapidly evolving technologies across various industries. While there is little consensus as to what knowledge actually is, its accumulation, transformation and valuation lie at the heart of intellectual capital management (ICM). It has come to play a predominant role in defining the productive power of corporations and it accounts for an increasing proportion of their capital.

The accounting expression for the knowledge resource discussed above is commonly referred to as 'intangible assets' or as 'intellectual capital' (IC). The term IC has many complex connotations and is often used synonymously with intellectual property (IP), intellectual assets and knowledge assets. IC can be classified into two categories: - human capital and structural capital (Best Practices in Knowledge Management, GIGA Information Group, 1997). This categorization can be illustrated within a knowledge management framework as illustrated in Figure 1.

Figure 1: A Knowledge Management Framework

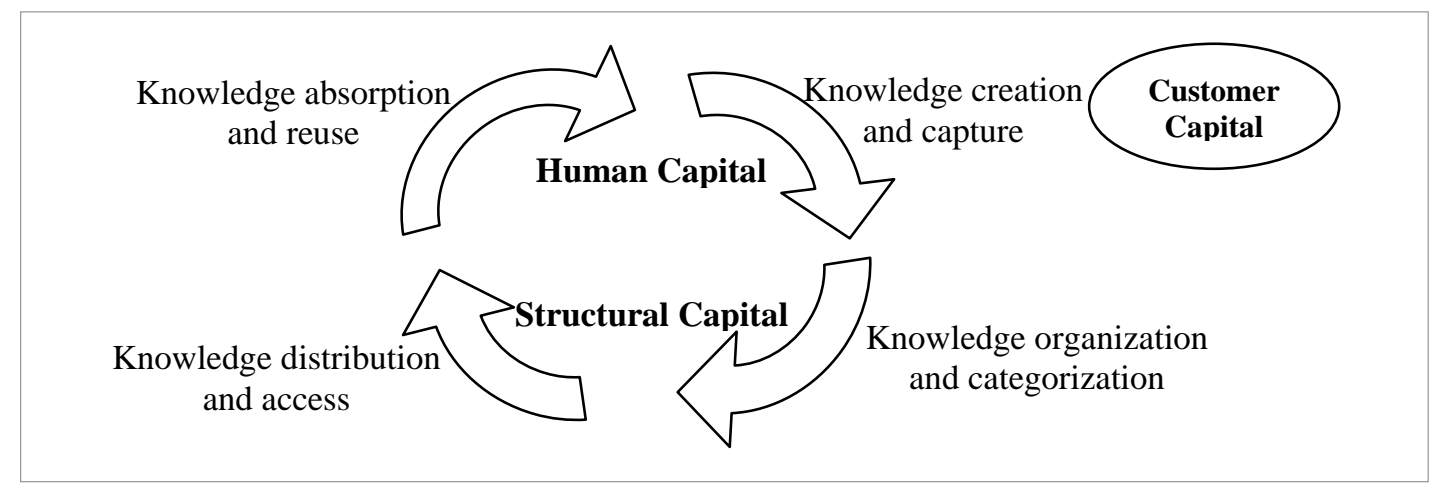

\footnotetext{
• Faculty of Business and Law Multimedia University Melaka, Malaysia Phone: +606252-3740 +606-2318869

E-mail: velmurugan@mmu.edu.my
} 
Human capital or intangible capabilities are defined as those distinctive factors of competitive advantage that differentiate a business from its competitors. They deal with the people aspects of knowledge management. Examples include: human resources or employee know-how, customer satisfaction, trade secrets \& consulting processes, and market competences.

Structural capital are defined as those assets which have enforceable ownership rights - this means they can be bought, sold, stocked in disembodied form and they can also be securitized. Examples are: franchises, copyrights, patents, trademarks, brands, domain names, software and licenses. They have the human knowledge embedded in them by transforming them into tangible company goods. These assets are the only form of IC that can be objectively valued and are recognized for accounting purposes.

Hence from these definitions, IC can be viewed as both the end result of a knowledge transformation process or the knowledge itself that is transformed into IP or intellectual assets of a firm.

\section{Research Problem}

The challenge that has formed the research problem of this paper is how corporations can effectively and reliably measure and report the value of intangibles on the balance sheet. The accounting profession is therefore losing relevance and 'face' since financial standards have not caught up to the demands of the KBE.

Below are some of the associated issues to the problem at hand.

- IC is not officially recognized: - accountants have typically dismissed human capital as too subjective a matter to include in company accounts. Hence the lack of a standardized valuation and reporting model. It is debatable whether this stand is well-founded on economic grounds or not.

- Intangible goods are often understated by accounting conventions by basing them on historical costs: - IP assets tend to be recorded at registration cost rather than their potential market value.

- When faced with the downsizing option, in spite of management and management gurus talk of employees being invaluable assets, it is incredibly difficult to actually put a figure on that value. The reality of most mind-sets in the industrial economy is that employees are still perceived as merely a means to maximize commodity output and not as invaluable resources.

- Due to automation, accounting has become a simplified task. The question has risen whether most financial professionals are deemed relevant or useful in this age. It stems from the fact that CIOs (Chief Information Officers) are becoming increasingly important due to the diversity of multiple functions in numerous fields being computerized.

\section{Objectives of the Research}

i. To draw attention to the challenges and problems posed to established accounting practices in measuring intangible assets brought about by the KBE. This entails examining accounting standards and assessing the impact the KBE has had on the role of accountants.

ii. To determine the implications of not accounting for IC against the decision to override reliability concerns and promote accounts that are inclusive of intangibles. The aim will be to ascertain whether the latter decision is of sufficient significance in useful decision making. 
iii. To find plausible valuation and reporting models or techniques that account for IC. This comprises of establishing whether existing models can be re-engineered to cater for intangibles; or if new proposals should take over. Inherent problems or objections (if any) to these proposed value reporting frameworks will be reviewed.

iv. To report any interesting developments or technologies brought about by the KBE to accounting.

\section{Survey of the Literature}

Chan Kit Whye (2000) reported coinciding views from a CPA standard setter and an academic in Singapore, on accounting for intellectual capital (IC) in the knowledge-based economy (KBE). The article stated that in a KBE, IC has become one of the most important intangible assets of companies, particularly for knowledge-based companies. The author examined a related article written by the academic reiterates the challenge to accounting standard setting bodies around the world. The author was of the opinion that accounting for intangibles or IC should enable companies to improve the management of their knowledge capital. Despite the obvious views shared by the author with professionals cited in the article, the debate was left as an open-ended question in the article without any strong recommendation on how to bring about this reporting change in accounting.

Serafin D. Talisayon (2002) outlined features or aspects linked to the ongoing shift to the knowledge economy in the article. The author recommended in the end that a change of mindsets is necessary before policies, structures and procedures can be changed. This point is stressed by quoting Gregory Bateson: "the problems in the world stem from the difference between how we think and how the world works". Such a mind-set change was exemplified by citing an example involving a new project undertaken by the National Statistical Coordination Board (NSCB) - the NSCB is a Philippines government agency that is responsible for monitoring the economy and computing GNP statistics. It plans to develop a second satellite accounting system which will be geared to track IC in the knowledge based economy. The author only mentioned 'positive' facets and excluded the negative or adverse implications that can arise from shifting to the knowledge economy.

James Guthrie, Richard Petty, and Ulf Johanson (2001) presented two main research aims in their paper: - to stimulate further accounting and management research regarding IC; and to draw attention to the gaps in the research literature. As a result, they ended up examining possible new ways of accounting for intangibles within the public and private sectors. The authors reviewed the changes to the business landscape that have created the demand for greater accountability and transparency regarding the IC that resides in organizations. The authors highlighted the need for financial and management practices to adapt to new performance measurement systems that focus on IC in an effort to re-engineer the traditional reporting process. Despite the authors' commendable efforts in succeeding to meet their goal of drawing attention to the gaps in the research literature, they stopped at what they termed as 'first-stage efforts' of consciousness-raising. Their scope did not go beyond this step by making solid recommendations on the way forward based on the research efforts they reported.

CA-TECHNET/FASB reported that New Economy leaders of technology companies (especially those from Silicon Valley, USA) have warned that proposed changes by the FASB to long-standing corporate accounting rules make it tougher for their companies to grow. FASB's proposals were viewed as a direct frontal assault on talented professionals and great ideas that have build and fueled the KBE.

The two main changes FASB reviewed were: 
i. Accounting for business combinations: - eliminate the use of the 'pooling of interests' method of accounting in corporate mergers and acquisitions; and

ii. Accounting standards for stock-based compensation: - re-price options to record the difference between the new lower price and any subsequent increase in the share price as an expense.

Jan Mouritsen (2002) raised the paradox of widespread conviction that IC and intangible assets are not appreciated by capital markets despite surveys revealing opposing sentiments. The paper focused on highlighting the point that the circulation of IC acceptance is blocked or inhibited by a number of problems. The author suggested a solution for better IC appreciation - a process consisting of two elements: disentanglement and entanglement. The author also attributed one reason capital market participants have problems with understanding IC to be linked to the fact that its trajectory into the future is hardly linear - an 'overflow' occurrence. Additionally, since overflow is said to affect an entangled resource such as IC, there is a need to disentangle it to make it manageable by traditional standards. Yet this of course presents another problem of losing the 'value' that comes from the unity brought about by the entanglement property, since individual components lose their intended meaning and hence their power by becoming something different.

Per Nikolaj Bukh (2002) reported the findings of a study conducted from 1990, which involved the IC reporting experiences of up to 100 large Danish firms (by 2002) quoted on the stock exchange. The aim of the project was to develop a set of guidelines for the development and publication of IC statements in Danish prospectuses. This was found to be ironic since IC reports and recent prospectuses share remarkable similarities with respect to the IC indicators disclosed. The author further stated that an IC report cannot only be read by comparing indicators between firms because strategies and value creation models are likely to differ between firms. Hence the paper advised that if competitive advantage is to be found in the development and implementation of the business model, then this becomes the natural starting-point for structuring IC disclosure.

Hadi Helmi Bin Zaini Sooria, A. S. Saravanan and A. Seetharaman (2002) formulated two main research objectives which were addressed to a large extent. The first was to identify how IC is measured and reported in the financial statements; and the second was to assess whether the current accounting and financial reporting framework is adequate to undertake challenges posed by the emerging IC economy. Research showed that efforts to value IC at economic value have generally been complicated, subjective, fraught with difficulties, and unsuccessful, due to a lack of understanding of the nature of IC and uncertainties surrounding it. The article explored some classification techniques that are widely quoted in IC literature. The authors concluded that despite limitations, internal users should be encouraged to a certain extent to start experimenting by measuring and reporting their IC progress, as they have access to internal IC development and records. With regard to external reporting, the authors concluded that in the interim, businesses and the general public would have to accept the limited knowledge on IC around the world.

Siebren M. Zijlstra and Jeltje van der Meer-Kooistra (2001) proposed an IC reporting model, so as to contribute to the research development in this area. The paper introduced the subject matter by stating that when external stakeholders lack information about a company's value, adverse consequences may result due to the stakeholders making wrong or bad investment decisions. The paper analyzed various reporting models that have been recently developed and are used in practice. The authors intended to develop both an internal and external reporting framework on IC, which they believed should be grounded in the management processes of IC resources. The authors focused on the requirements an external IC report 
should meet - owing to its increased cost characteristics and tax consequences. In spite of the authors' brave attempt to come up with a IC reporting model, they concede in the end that further research is required as IC theory is still in its infancy and hence it is not possible to develop a comprehensive reporting framework for the time being.

Ellen Masterson (2001) described the Value Reporting ${ }^{\mathrm{TM}}$ approach created by PricewaterhouseCoopers in collaboration with clients, analysts and academics. The article examined ways in which this reporting approach could be used by the insurance industry as a source of competitive differentiation and in providing enhanced value. It was stated that this could be achieved by identifying performance measures that demonstrate value creation for investors and then communicating this information in an open, timely and consistent manner. The author evaluated the effectiveness of disclosure within the industry by identifying communication problems between insurers and the market which were classified under five communication gaps: - quality, understanding, information, perception and reporting. The article underlined the benefits to insurers by developing a Value Reporting ${ }^{\mathrm{TM}}$ framework so as to avoid the risk of seeing investment go elsewhere; however, the approach seems to involve a painstaking process that requires continuous evaluation and enhancement. In the researchers' defense, it can be argued that complicated means have to be resorted to in order to survive in this competitive knowledge-driven economy.

Christopher Kuhner (2002) identified new plausible financial accounting standards relevant to the new economy which have become debatable in the accounting industry. The paper revealed evidence from numerous empirical studies showing that accounting figures (equity as well as earnings measures) have lost value relevance. The author noted that from a matching-principle viewpoint, capitalizing expenditures for intangibles as delayed charges would imply exact measurement of changes of the firms' intangible capital. In contrast, the rise of measuring intangible assets using the fair value paradigm as the financial accounting concept could lead to a substantial change in the role of financial accounting and auditing. Yet it is debatable whether such a change in the role of the accounting and auditing profession will strengthen the quality and integrity of financial accounting. The author concluded that accounting for intangible assets is therefore an entrepreneurial task. The paper satisfactorily presented both pros and cons to the debate under review.

\section{Research Methodology}

The information of the research project was gathered from various secondary sources of data. All the articles were downloaded from online journals, periodicals, reports and white-papers published in magazines, databases and newspapers. The sources range from: industry trade journals; practitioner accounting journals; and academic publications, to give both practical and theoretical views on the subject matter. 
Figure 2: Research Framework

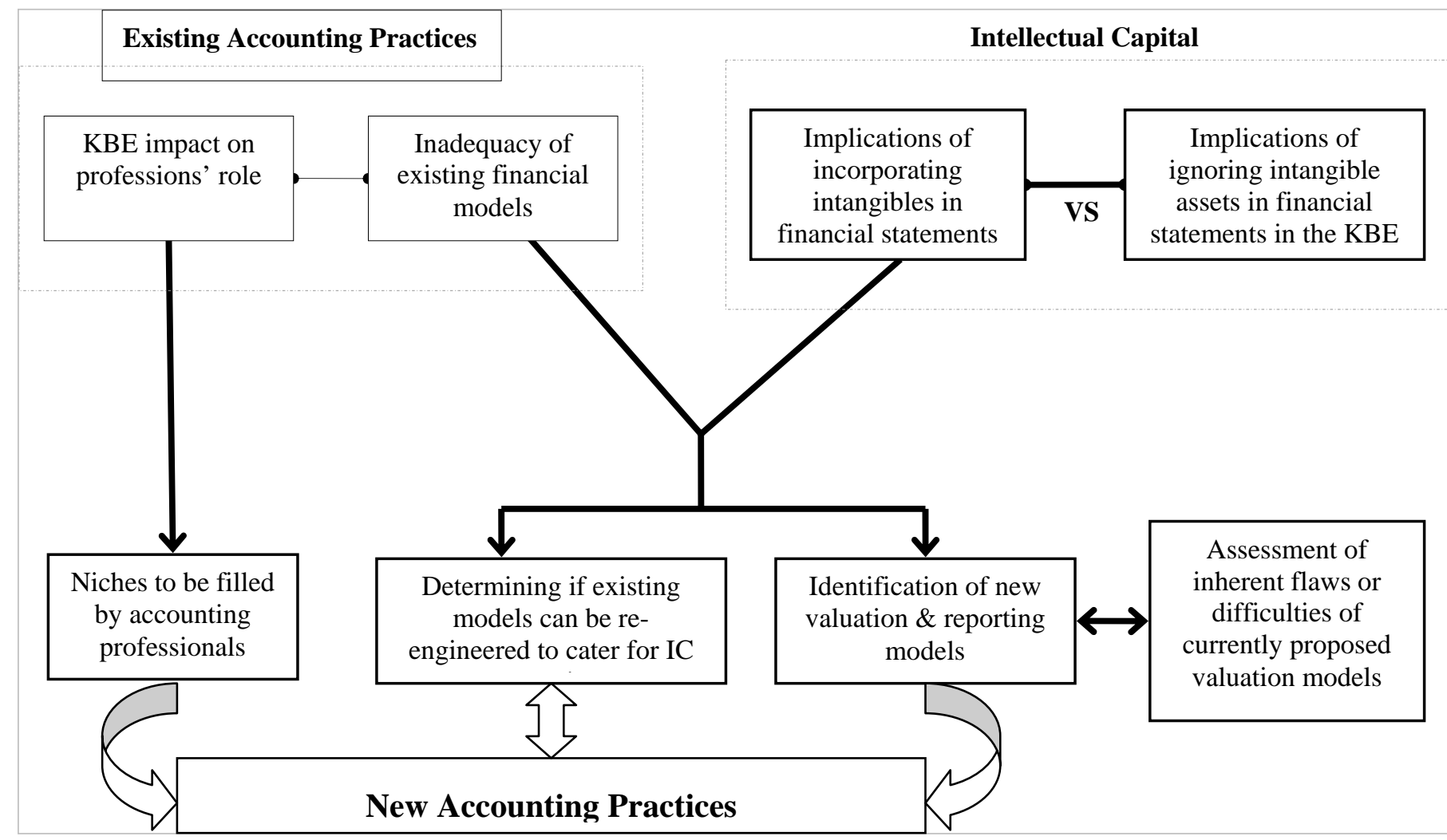

\section{Discussion, Analysis and Finding}

This section of the paper will explore in great detail the various aspects that make up the research framework. A comparison will first be made that looks into the limitations of existing financial models and the subsequent implications of ignoring IC in financial statements versus the significance of accounting for IC. The second part entails comparing IC valuation techniques using conventional reporting standards against proposed new reporting methodologies. From this discussion, a conclusion will be drawn which will include a proposition of a way forward in addressing IC.

\section{Limitations of Existing Financial Models}

The implications of ignoring IC are numerous; below are just some of the deficiencies of existing financial models.

- Balance equity share numbers have lost value relevance in terms of their predictive power for the explanation of abnormal returns (Kuhner 2002). Since the present accounting model does not measure the creation of value but rather its realization, companies that invest heavily in IP assets are most affected because they are unable to express this value in their accounts.

- The limitations that surfaced were when FASB recently proposed a rule that eliminated the use of the 'pooling of interests' method of accounting. This method deals with corporate mergers and acquisitions; and its termination was met with a lot of resistance from technology industry leaders (CA-TECHNET/FASB). Arguments raised against FASB's proposal were that:

- FASB's proposal to eliminate pooling would mischaracterize all mergers as purchases, and thus conflict with FASB's mission to develop "neutral standards 
that result in accounting for similar transactions and circumstances similarly and for different transactions and circumstances differently".

- FASB's proposal will not improve the financial statement information that investors rely upon.

- Altering these accounting principles could adversely impact the New Economy by discouraging mergers and acquisitions that foster efficiency, innovation, creativity and growth.

- The business combination rules, in conjunction with proposed changes to the rules on stock option standards, would make it tougher for tech companies to attract and retain the skilled workforce they need, driving employees away from small companies and hurting economic growth.

\section{Significance of Accounting for IC}

There is a growing awareness that IC adds significantly to the value of a business and in some cases, represents almost the entire value base: - knowledge has become what we buy, sell and do. Interest in IC is promoted for many reasons, and below are some of them.

- In order to better understand the internal dynamics within organizations, studying IC has become necessary. Intangible assets have taken on a new and unprecedented importance in a world redefined by global competition: - this is driven by the need for constant strategic adaptation, ever-increasing customer demands, and an explosion of service-based industries (Guthrie et. al., 2001).

- In the KBE, an understanding of the correlation between human development and knowledge innovation productivity is important. It is so because investing in human capital could affect a company's future performance and value - hence not all expenditure is consumption or wastage and not all forms of maintenance are expenses. The irony is that while industrial assets depreciate with use, knowledge assets appreciate with use.

- Another benefit of IC reporting is that it enhances transparency which could further lead to more accurate assessments of 'true' share prices (i.e. reduced market volatility) leading to lower investment risk and cost of capital. Transparency in communications could further be viewed by financial analysts as a sign of strength as it inspires a sense of trust and integrity among the workforce and other stakeholders.

- IC reporting offers more information which could be interpreted as a positive representation of management's commitment in realizing their goals. The IC report could also be used as a strategic marketing tool, or as a monitoring tool of a company's long term performance.

- In the case of mergers, a 'fair' valuation of IP rights is important for all parties concerned, such that one company doesn't overpay and the other undersell. This point was illustrated in the classic Time Warner/AOL deal.

- When faced with downsizing staff, IC valuation is an important factor to consider since it could affect a company's profit generation capability in the near future - short-term cost savings should be compared with long-term benefits.

\section{IC Valuation and Reporting}

The challenge at this stage is to consolidate IC research and find coherent policies on measuring and reporting IC within public and private sector organizations. This can be achieved in two ways that will be explored next: - adopting existing standards to represent IC 
or finding possible new ways of accounting for intangibles. With regard to the latter, executives in Canada, Australia and several European nations (especially Sweden and Denmark since 1994) have moved forward in measuring IC. The accounting reports of some of these companies place heavy emphasis on the application of non-financial metrics with regard to IC, thereby deviating significantly from the traditional management and accounting orthodoxy (Mouritsen, 2002).

\section{Existing Financial Models Accommodating Intangible Assets}

- Rennie (1999) suggested the establishment of a "statement of investments in the future". This is a variation of the cost approach which books IC costs as assets and amortizes them over time. In other words, IC is capitalized or charged to the profit \& loss account, depending upon whether incurred expenses buffered for a period of three to five years prove to be expenses or investments.

- The market-to-book ratio is a simple approach that assumes to measure IC in its totality by valuing intangible assets at market share valuation less the book value of tangible assets.

- A similar approach to the market-to-book ratio that tries to capture the total IC value is referred to as market-to-replacement cost ratio. This approach looks at comparable cash flows to try to find pricing levels on similar types of projects (e.g. mergers and acquisitions), or by determining the difference between results of a given company and an average competitor employing comparable tangible assets. An alternative approach is to base the valuation on working out a replacement value, which is determined by weighing the decision against the cost of building something similar from scratch.

- The discounted cash flow approach values IC at economic value. This approach is preferred by economists and entrepreneurs because they believe the economic value base best supports investment philosophy. However, its major drawback is that it is subjective and highly risky as it is dependent upon future estimations and assumptions which often prove to be wrong.

\section{New Models and Strategies to Measure and Report IC}

- The Enhanced Business Reporting model was developed by a special committee elected by the American Institute of Certified Public Accountants (AICPA) since September 2002, which was to enhance the current reporting model. Efforts to enhance business reporting fall within the conceptual framework illustrated by the diagram below, whereby the model is represented by the convergence of five elements: - System Reliability; Financial \& Non-Financial Measures; Information Dissemination; Understandable Disclosures and Corporate Accountability. 
Figure 3: Enhanced Business Reporting Model

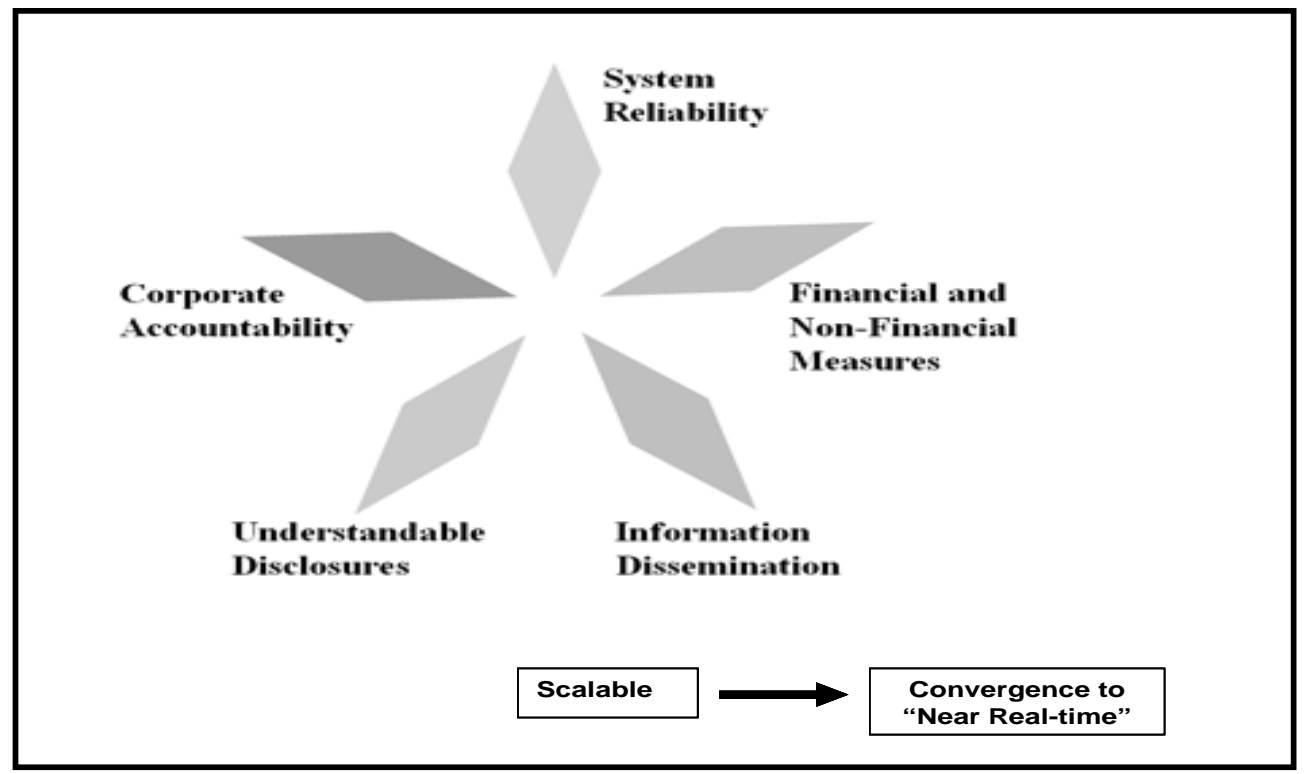

(Source: http://www.aicpa.org/innovation/scebr.htm )

The diagram also demonstrates attributes of scalability and convergence in the conceptual business reporting framework. Depending on the size and needs of the organization, any combination of the five elements and with varying degrees can be selected to provide a comprehensive, understandable picture of a company's priorities, challenges, accomplishments, risks and financial position. For instance, large corporations would likely undertake efforts within all five elements.

- IC disclosure: - a strategic framework for disclosure is offered by the concept of business models. Although they are coupled with e-business, business models do a lot more by explaining a firm's goal, its value proposition, and its interaction of creating value with factors within its organizational environment. The business model assumes an important role when competitive advantage is to be found in its development and implementation; hence, it can be the natural starting-point for structuring disclosure of IC (Bukh 2002). For instance, new value creation models would be formulated with an understanding of the value created from knowledge resources (IC) derived from an environmental factor such a firm's customers.

- Total Quality Management (TQM) is a highly subjective method designed to assist management by using various human resource development (HRD) and organizational development (OD) indicators or measures (Green, 2003). In simplified terms, TQM = HRD + OD.

- Economic value added (EVA) is a value-based management tool that determines whether operating profit is enough compared to the total costs of capital employed. Is uses a simple equation (or slight variations of it) to assess this value(Tobin,Lanfranconi 2001).

Net operating profit after taxes (NOPAT) less capital charge:

$\mathrm{EVA}=$ NOPAT - CAPITAL COST $\Leftrightarrow$

EVA $=$ NOPAT - COST OF CAPITAL x CAPITAL employed (1) 
The logic behind EVA is that shareholders must earn a return that compensates the risk taken or similarly risky investments at equity markets.

- Strassman’s KCV (Knowledge Capital Value) method attempts to measure IC in totality based on the prospective economic value. It measures IC value as follows:

$$
\begin{aligned}
\mathbf{K C V}= & \frac{\text { risk adjusted interest in future earnings }- \text { cost of capital }}{\text { price of capital for both financial and knowledge investments }} \\
= & \text { management value added / price of capital }
\end{aligned}
$$

- The Canadian Institute of Chartered Accountants' (CICA) Total Value Creation ${ }^{\mathrm{TM}}$ (TVC) measures and reports on value-creation performance. Using elaborate models, the system helps management by tracking down financial and non-financial performances and then it reports alternative scenarios such that the one that creates the most value is chosen. CICA feels TVC is more advanced than the Economic Value Added (EVA) and Balanced Scorecard models - it is claimed that it can be incorporated into an ERP system or existing accounting packages.

\section{KBE Impact on the Role of the Accounting Function \& its Professions}

Some of the specific ways in which accountants are affected by changes in the KBE and the ways they can participate in the $\mathrm{KBE}$ are following:

Redefining the CMA/CFO product: - critical success factors of the CMA include market relevance, recognition, differentiation, member competence, quality growth and operational excellence. Besides being perceived as business professionals who are experts in their own right than mere treasurers, they need to address challenges facing them in the globalized knowledge economy. Today's business environment demands much more of accountants they are expected to be innovative strategists; business leaders; and be system designers (for example, combining accounting knowledge with information systems in an ERP environment). The complex evolving role of the CFO exemplifies the cross-functional intertwining of strategy, finance, IT, HR and e-business. To reflect the broader nature and complexity of the risks that most firms now face, some critics have gone as far as stating that the CFO's job should be scrapped and replaced by that of a chief risk officer (CRO).

Management accountants and other management professionals can contribute by proactively managing IC as well as value-added external reporting. They should assume a foresight role which entails studying long-term fiscal challenges and understanding the impact of IC on business operations. In doing this, they lessen investment risks and potentially activate higher returns on investment. To accomplish this, they first need to recognize the importance of IC, its hidden value, as well as potential benefits to be derived in the future.

In order to lead the way in the establishment of a universal IC reporting framework, accounting professionals need to form strategic global alliances since mutual experience benefits all parties concerned. For this to be successful, cooperation needs to extend to everyone in the public, private and non-profit sectors.

Treasurers have to start thinking about human capital risk in a holistic way in the new economy. It could be a significant move in the accounting world if a treasurer thought less like an actuary by applying a creative approach to the issue of IC, since they would appreciate the implicit risk involving IC. 
Last but not least, governments can contribute by reducing barriers to private sector efforts to overcome problems with IC disclosure. While business bears the primary responsibility for developing better metrics for measuring business and economic performance, government can contribute by enforcing transparency in corporate disclosure and by adjusting IP laws. For instance, new regulations such as the Sarbanes-Oxley Act of 2002 were introduced to combat mismanagement and fraud by ensuring forecasts and reports are validated and accurate.

\section{Other Points of Interest Brought About by the KBE to Accounting}

\section{Taxes}

Taxing is one area the KBE influences the accounting function. Lawson (2003) says that in addition to property taxes, inevitably governments will be forced to enact broad-based sales taxes and charge user fees to fund government functions. Further more, they might ultimately eliminate the income tax and other distorting selective taxes that drive out high-income earners and small businesses. Internet technology and global markets enables e-businesses to leave if they want to; this mobility explains why businesses have become so successful at extracting tax concessions from state and local governments.

\section{Business Performance Management (BPM) Systems}

Another area of interest has been raised by Hyperion Solutions Corporation (2003) in stressing the importance of business planning in today's uncertain economy in terms of ensuring forecasts and reports are validated and accurate. Hyperion argued is not achievable with conventional tools such as general ledger/ERP, spreadsheets, OLAP (online analytical processing) tools and packaged applications. The inadequacies of the four above mentioned tools were highlighted; for example, HSC claims that studies show that $20 \%$ to $40 \%$ of all spreadsheets contain errors. Hence, a paradigm shift was recommended in the form of Business Performance Management (BPM) systems. It is alleged that these systems are optimized to cope with change by combining the strength of transaction systems such as ERP with the power and sophistication of a predictive intelligence suite. Hyperion also listed best practices in business planning, as well as how BPM software supports these practices:

- driver-based planning;

- linking business strategy to operational targets ;

- connecting cross-functional areas of the business;

- rolling forecasts;

- central platform and data repository; and

- Scorecards and performance key indicators.

\section{Communications Accounting Systems}

Tarro (2001) explained how event-based communications accounting systems can help convention and show managers become local resellers of communications bandwidth and network based content and services. These systems create on-premise technology service providers with identifiable billable activity on a network as it occurs; apply local pricing policy, and cut invoices or post charges to financial and property management systems.

These systems are likened to a toll-booth on a freeway - their position allows real-time billing to occur on the property, and not from distant ISPs and web sites. Communications accounting systems enable the independent aggregation, reservation and delivery of a number of digital services to visiting groups and individuals. As an operator of a communications 
accounting system, they can provide real-time usage-based billing of all technology services delivered to each visiting group, with pricing specific to each event.

\section{Enforcement of New Regulations}

As from 2005, new imminent market regulations that will be enforced by the International Financial Reporting Standards (also referred to as the International Accounting Standards) are going to be imposed on all listed financial service companies in the European Union (Huber, 2003). The point is to promote transparency of company's financial statements to investors and analysts, such that it will be easier to compare a company's performance with that of other firms. The regulations include a new banking code to tighten-up risk management, international accounting standards and a registration overhaul for the general insurance market. The new regulations will replace the Generally Accepted Accounting Principles (GAAP) standards used by each country to prepare accounts. It is estimated that more than 7,000 companies and their financial information and accounting systems will be affected.

\section{$X B R L$}

A data standard that is currently growing in popularity in financial reporting circles is XBRL (Extensible Business Reporting Language). XBRL is promoted to be the future standard for the electronic distribution and comparison of business reports \& financial performance of groups of companies. However, it is criticized for its complexity which is causing its slow adoption. Another major drawback is the current lack of a common accounting standard. XBRL is meant to represent financial information prepared in accordance with accounting standards; as present standards vary, it is unfortunate that it may be impossible to compare company performances (Huber, 2003).

\section{Conclusion}

Initial efforts focusing on consciousness-raising have largely succeeded by making IC a topic worthy of boardroom discussion and one that deserves the full attention of researchers as a legitimate undertaking. Although various reporting models on IC have recently been developed, it is clear that the one-size-fits-all concept of financial reporting is inappropriate for IC. This basis can form the distinction between internal and external IC reports that account for organization's value creation. Government and accounting bodies can work together to come up with universal legislation and financial accounting regulations for external reporting. Whereas internal reports can be detailed and contain much sensitive company-specific information, external reports need to follow general and systematic guidelines that will assist auditors (and other people) concerned with uniform readability, interpretation and fair comparison of companies' performance and true value. The aim is to combat mismanagement and fraud by ensuring forecasts and reports are validated and accurate.

A coherent unambiguous policy for IC reporting would facilitate consistency and raise the bar to create accountability, visibility, communication, and predictability or reduction of risk surrounding intangibles. Other solutions lie with the changing role of the accounting professional: - higher expectations imply the probable need for CFOs to think like strategic leaders by upgrading their skills to be more technology oriented; as well as assuming integrity and honor in executing their job. A simple lesson from history that can be applied to the business environment in the $\mathrm{KBE}$ is that those who face change and reality survive, whereas those who resist it get eliminated or fall to ruins.

\section{References}


Bin Zaini Sooria, H.H., A. S. Saravanan, and A. Seetharaman (2002), "Intellectual capital accounting and reporting in the knowledge economy”, Journal of Intellectual Capital, Vol. 3 Iss. 2, pp. 128-149

Birkner L.R. (2000), “Knowledge capital measures and EH\&S”, Occupational Hazards, Vol. 62 Iss. 8, pp. 49-51

Bucklew, M. and Edvinsson, L., “Intellectual capital at Skandia” URL: http://www.fpm.com/cases/el3.html

Bukh, P.N. (2002), “The relevance of intellectual capital disclosure: a paradox?” http://www.pnbukh.com/PDF_ARTIKLER/the_relevance_of_intellectual_capital.pdf

CA-TECHNET/FASB, "New Accounting Rules Could Hurt Tech Start-Ups and Small Companies, Impact Industry and U.S. Economic Growth, Tech Industry Leaders Testify" http://www.soho.org/Technology_Articles/Rules_Hurt_SB_Tech.htm

Garcõ-Ayuso, M. (2003), "Factors explaining the inefficient valuation of intangibles”,Accounting, Auditing\& Accountability Journal, Vol. 16 No. 1, pp. 57-69

Green, L. (2003), “A Simplified TQM Diagnostic Model” URL http://www.skyenet.net/ leg/tqm.htm

Guthrie, J., R. Petty, and U. Johanson (2001), "Sunrise in the knowledge economy”, Accounting, Auditing \& Accountability Journal, Vol. 14 Iss. 4, pp. 365-383

Huber, N. (2003), "Flurry of new accounting rules set to keep financial sector IT directors on their toes" http://www.computerweekly.com/Article122825.htm

Hyperion Solutions Corporation (2003), "Business Planning in an Uncertain Economy” http://wp.bitpipe.com/resource/org 971714689_543/BusinessPlanning bitpipe.pdf

Kuhner, C. (2002), "New Financial Accounting Standards for the New Economy? - Some Remarks on the Ongoing Debate” http://www.wiso.uni-koeln.de/treuhand/forschung/SchriftenvzBeitragHagen.pdf

Latour, B. (1999), "Pandora’s Hope. Essays on the Reality of Science Studies”, Harvard University, Press, Cambridge, MA

Mäkeläinen, E. (1998), “Economic Value Added as a management tool” URL: http://www.evanomics.com/

Masterson, E. (2001), “Closing the information gap”, Insurance Digest, pp. 4-7 http://www.pwcglobal.com/extweb/pwcpublications.nsf /4bd5f76b48e 282738525662b00739e22 le5525cae69a19c0585256a2c001d10ed /\$FILE/US\%20Digest\%20\%20final.pdf

Mouritsen, J. (2002), "Intellectual capital and the capital market: the circulability of intellectual capital” http://www.euintangibles.net/library/localfiles/WP6/6.2_Mouritsen_2003a.pdf

Rennie, M. (1999), “Accounting for knowledge assets: do we need a new financial statement?”, International Journal of Technology Management, Vol. 18, Nos.5/6/7/8

Talisayon, S.D. (2002), “Knowledge and People”, Business World, pp. 1

Tarro, R. (2001), “Internet Strategy for the Event Manager - Communications Accounting Technology and the Emergence of On-Premise Service Providers” URL: http://www.sddsystems.com/whitepapers/wpStrategies\%200n\%20Internet\% 20Billing\%20For\%20Events.pdf

Walker, D.M. (2002), “21st century challenges and opportunities”, International Journal of Government Auditing, Vol. 29 Iss. 3, pp. 1-2

Whye, C.K. (2000), “Accounting In The Knowledge-Based Economy”, Singapore Accountant http://accountingeducation.com/news/news928.html

Zijlstra, S.M., and J. van der Meer-Kooistra (2001), "Reporting on intellectual capital”, Accounting, Auditing \& Accountability Journal, Vol. 14 Iss. 4, pp. 456- 477. 